\title{
Advanced fabrication of hyperbolic metamaterials
}

Shkondin, Evgeniy; Sukham, Johneph; Panah, Mohammad Esmail Aryaee; Takayama, Osamu; Malureanu, Radu; Jensen, Flemming; Lavrinenko, Andrei

\section{Published in:}

Proceedings of International Conference on Metamaterials and Nanophotonics, METANANO 2017

Link to article, DOI:

$10.1063 / 1.4998025$

Publication date:

2017

Document Version

Publisher's PDF, also known as Version of record

Link back to DTU Orbit

Citation (APA):

Shkondin, E., Sukham, J., Panah, M. E. A., Takayama, O., Malureanu, R., Jensen, F., \& Lavrinenko, A. (2017). Advanced fabrication of hyperbolic metamaterials. In Proceedings of International Conference on Metamaterials and Nanophotonics, METANANO 2017 (Vol. 1874). [020004] American Institute of Physics Inc.. A I P Conference Proceedings Series Vol. 1874 https://doi.org/10.1063/1.4998025

\section{General rights}

Copyright and moral rights for the publications made accessible in the public portal are retained by the authors and/or other copyright owners and it is a condition of accessing publications that users recognise and abide by the legal requirements associated with these rights.

- Users may download and print one copy of any publication from the public portal for the purpose of private study or research.

- You may not further distribute the material or use it for any profit-making activity or commercial gain

- You may freely distribute the URL identifying the publication in the public portal 


\section{Advanced fabrication of hyperbolic metamaterials}

Evgeniy Shkondin, Johneph Sukham, Mohammad E. Aryaee Panah, Osamu Takayama, Radu Malureanu, Flemming Jensen, and Andrei V. Lavrinenko

Citation: AIP Conference Proceedings 1874, 020004 (2017); doi: 10.1063/1.4998025

View online: http://dx.doi.org/10.1063/1.4998025

View Table of Contents: http://aip.scitation.org/toc/apc/1874/1

Published by the American Institute of Physics

\section{Articles you may be interested in}

Race for novel high-index all-dielectric and hybrid metal-dielectric nanophotonic materials: Pit-stop optical tests AIP Conference Proceedings 1874, 020003 (2017); 10.1063/1.4998024

Metamaterials for opto-acoustic interactions

AIP Conference Proceedings 1874, 020006 (2017); 10.1063/1.4998027

Effect of substrate on optical bound states in the continuum in $1 \mathrm{D}$ photonic structures AIP Conference Proceedings 1874, 030005 (2017); 10.1063/1.4998034

Spatially-dispersive surface modes on interfaces of layered hyperbolic metamaterials AIP Conference Proceedings 1874, 040040 (2017); 10.1063/1.4998113

Photonic quantum walks with symmetry protected topological phases AIP Conference Proceedings 1874, 020001 (2017); 10.1063/1.4998022

In-situ fabrication of polymer/metal nanocomposite films using a mid-infrared laser AIP Conference Proceedings 1874, 020005 (2017); 10.1063/1.4998026 


\title{
Advanced Fabrication of Hyperbolic Metamaterials
}

\author{
Evgeniy Shkondin ${ }^{1}$ and Johneph Sukham ${ }^{1}$ and Mohammad E. Aryaee Panah $^{1}$ and \\ Osamu Takayama ${ }^{1}$ and Radu Malureanu ${ }^{1}$ and Flemming Jensen ${ }^{2}$ and Andrei V. \\ Lavrinenko ${ }^{1,3, a)}$
}

\author{
${ }^{1}$ DTU Fotonik, Department of Photonics Engineering, Technical University of Denmark, Oersteds Plads 343, \\ DK-2800 Kgs. Lyngby, Denmark \\ ${ }^{2}$ DTU Danchip - National Center for Micro- and Nanofabrication, Technical University of Denmark, Ørsteds Plads \\ 347, DK-2800 Kgs. Lyngby, Denmark \\ ${ }^{3}$ International Research Centre for Nanophotonics and Metamaterials, ITMO University, St. Petersburg, Russia. \\ a) alav@fotonik.dtu.dk
}

\begin{abstract}
Hyperbolic metamaterials can provide unprecedented properties in accommodation of high-k (high wave vector) waves and enhancement of the optical density of states. To reach such performance the metamaterials have to be fabricated with as small imperfections as possible. Here we report on our advances in two approaches in fabrication of optical metamaterials. We deposit ultrathin ultrasmooth gold layers with the assistance of organic material (APTMS) adhesion layer. The technology supports the stacking of such layers in a multiperiod construction with alumina spacers between gold films, which is expected to exhibit hyperbolic properties in the visible range. As the second approach we apply the atomic layer deposition technique to arrange vertical alignment of layers or pillars of heavily doped $\mathrm{ZnO}$ or TiN, which enables us to produce hyperbolic metamaterials for the near- and mid-infrared ranges.
\end{abstract}

\section{FABRICATION OF HYPERBOLIC METAMATERIALS}

Typically hyperbolic metamaterials are presented by a layered multi-periodic media or by a bundle of nanopillars or nanowires $[1,2]$. The alteration of conducting (for example, metals, transparent conducting oxides or heavily doped semiconductors) and dielectric (air, oxides or high-resistive semiconductors below the bandgap) insertions should obey the principle condition for the homogenization legitimacy - it must happen on scales much smaller than the operating wavelength. Therefore, optical metamaterials, and hyperbolic metamaterials in particular, require extremely small thicknesses of the layers (down to $10 \mathrm{~nm}$ and even below) or lattice periods and diameters of the wires/pillars. Needless to say, that fabrication of the unitary elements must be accompanied with a very low roughness of the surfaces.

\section{Ultrathin Gold Layers}

Gold is considered to be a backbone of plasmonics due to it conformal deposition, low material losses, inert behavior towards most of substances and open-air stability. So deposition of nanometers-thick gold films can be performed by sputtering techniques $[3,4]$ after a special preprocessing of the working surface with layers improving

Proceedings of International Conference on Metamaterials and Nanophotonics (METANANO-2017)

AIP Conf. Proc. 1874, 020004-1-020004-3; doi: 10.1063/1.4998025

Published by AIP Publishing. 978-0-7354-1554-6/\$30.00 
adhesion of gold to the substrate. Conventionally the $\mathrm{Ti}$ or $\mathrm{Cr}$ adhesion layers are in use. However, when the thicknesses of the film become very small, the properties of the adhesion layer can deteriorate the overall performance of the structure towards, e.g. surface or bulk plasmon-polariton propagation or localized surface plasmons Q-factors [5].

We proposed to use 3-Aminopropyl-trimethoxy-silane (APTMS) as an adhesion layer for gold, obtaining an ultra-thin, ultra-smooth gold film of the thickness of $6 \mathrm{~nm}$ and roughness below $0.30 \mathrm{~nm}$ [3]. We prove the superior quality of the layers deposited by our approach (Fig.1a) by detection of excitation of short-range surface plasmon polaritons. As a reference we use layers deposited with the Cr-adhesion or without any adhesion layer. As a next step in advancing technology we report on stacking of few periods of gold-dielectric bi-layers to deliver a highquality hyperbolic metamaterial prototype.

\section{Metamaterials with Vertically Arranged Elements}

Another principal geometry that supports hyperbolic behavior is the so-called wire medium, e.g. an anisotropic composite of metallic pillars incorporated in a dielectric host matrix. Its one-dimensional analogue - trenched structure - can also exhibit specific hyperbolic dispersion of surface waves. Unfortunately, sputtering of gold cannot be used in fabrication neither of vertically standing nanopillars, nor vertical layers when even a moderate aspect ratio of unitary elements is required. The processing of such metamaterials can be done by atomic layer deposition (ALD), but gold then must be substituted by alternative plasmonic materials, which allow ALD processing, for example, aluminum doped $\mathrm{ZnO}[6,7]$.

We report on fabrication of extended arrays of AZO nanotrenches and nanopillars, which can be considered as metamaterials, in particular, hyperbolic metamaterials in mid-IR. Such choice is regulated by the period size, which is $400-500 \mathrm{~nm}$ due to limitations of the deep-UV laser lithography (Fig.1b).

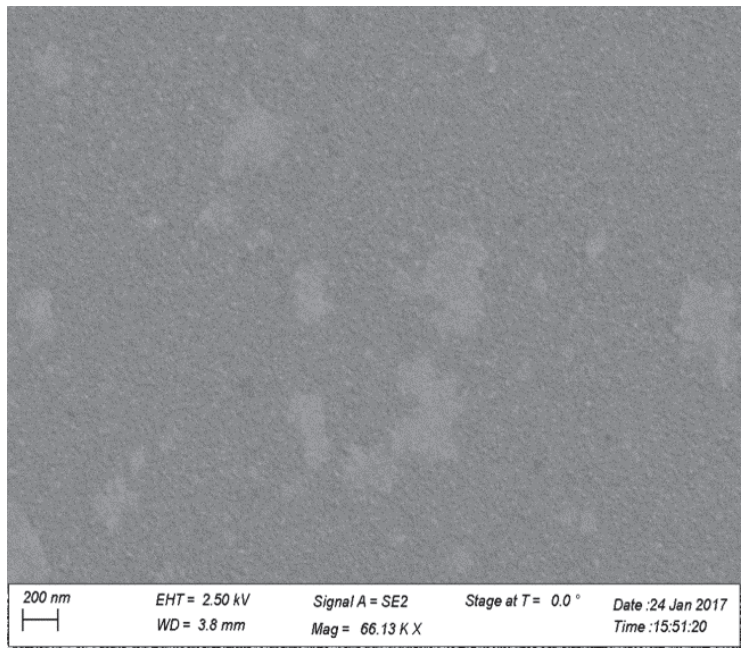

(a)

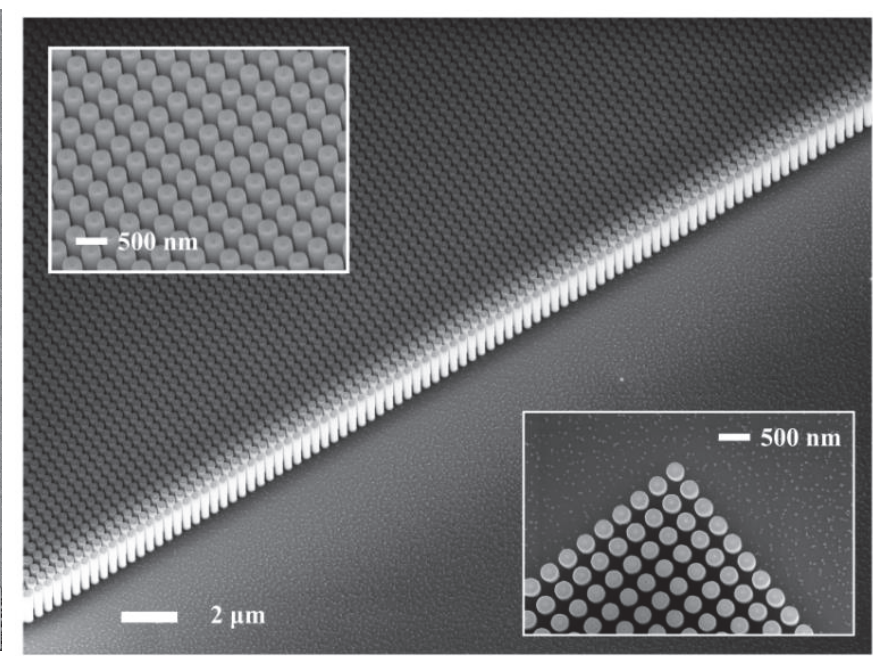

(b)

FIGURE 1. (a) $8 \mathrm{~nm}$ thick gold film deposited on APTMS adhesion layer; (b) Figure shows the bird-eye SEM image of finally prepared pillars, the insets shows the magnified image of pillars (top left) and top view of the array corner (bottom left).

Rather surprisingly, the tensor of the effective permittivity restored from the mid-IR reflectance spectra has a very strong anisotropy, but is positively defined. This astonishing discrepancy implies that AZO, once being confined in the nanopillar dimensions, becomes poor plasmonic material, and its permittivity significantly deviated from that of the flat film. So, this challenging fact poses a question of applicability of ALD deposited materials for hyperbolic metamaterials and definitely requires further attention. 


\section{ACKNOWLEDGMENTS}

This work (development of the technology) was supported by Villum Fonden "DarkSILD project No. 11116", Denmark, and, partially, by Russian Science Foundation, grant \#15-12-20028 (numerical simuations of hyperbolic metamaterials, AVL contribution).

\section{REFERENCES}

1. A. Poddubny, et al., Nature Photonics, 7, 958-967 (2013).

2. L. Ferrari, et al., Progress Quant. Electron. 40, 1-40 (2015).

3. L. Leandro, et al., ACS Appl. Mater. Interfaces 7, 5797-5802 (2015).

4. H. Qian, Y. Xiao, and Z. Liu, Nat. Commun. 7, 13153 (2016).

5. T. Desalegn, et al., Opt. Mat. Express, 7, 73-84 (2017).

6. E. Shkondin, et al., Opt. Mat. Express 7, 1606-1627 (2017).

7. O Takayama, et al., arXiv preprint, arXiv:1704.06108 (2017). 